\title{
Concepções de Deficiência e Reabilitação: um Estudo Exploratório com Graduandos de Fisioterapia
}

\author{
Concepções de Deficiência e Reabilitação
}

\author{
José Fernando Bitencourt Lomônaco \\ Ana Paula Martins Cazeiro \\ Andréia Menandro Ferreira
}

\section{Resumo}

O objetivo deste estudo foi identificar alterações nas concepções de deficiência e reabilitação de alunos do primeiro e do último ano de um curso de graduação em Fisioterapia. A amostra foi constituída por 67 alunos de uma universidade brasileira. Os alunos foram solicitados a escrever todas as características que lhe viessem à mente, num intervalo de um minuto e meio, diante das palavras deficiência e reabilitação. As respostas foram analisadas visando identificar aspectos comuns que permitissem a criação de categorias para $\mathrm{o}$ agrupamento dos dados. Computaram-se as diferenças entre as porcentagens de respostas do $1^{\circ}$ e do $4^{\circ}$ anos para cada categoria criada. Verificou-se que os alunos do $I^{\circ}$ ano citaram características mais ligadas ao senso comum e os do $4^{\circ}$ ano arrolaram um maior número de atributos de caráter técnico-científico. Os resultados foram discutidos em função da influência do curso de graduação nos conceitos analisados.

Palavras-chave: Conceitos; Reabilitação; teorias Psicológicas.

\section{Conceptions of impairment and rehabilitation: an exploratory study with physiotherapy undergraduates}

\begin{abstract}
The purpose of this study was to identify shifts on impairment and rehabilitation conceptions of sophomore and senior undergraduate physiotherapy students. The subjects were 67 students from a Brazilian university. They were asked to write all attributes that occurred to them in a minute and half interval, given the verbal stimuli impairment and rehabilitation. The responses were analyzed in order to identify their common features that allowed grouping data in categories. The differences between response percentages from sophomores and seniors for each category were computed. It was verified that the sophomores listed more characteristics related to the common sense and the seniors listed more technician-scientific attributes. The results were discussed in function of the influence of graduation course on the concepts analyzed.
\end{abstract}

Keyword: Concepts; Rehabilitation; Psychological theories.

\section{Concepciones de deficiencia y rehabilitación: un estudio exploratorio con estudiantes de fisioterapia.}

\section{Resumen}

El objetivo de este estudio ha sido identificar alteraciones en las concepciones de deficiencia y rehabilitación de alumnos del primer y último año de un curso de fisioterapia. La muestra ha sido constituida por 67 alumnos de una universidad brasilera. Ha sido solicitado a los alumnos a escribir todas las características que les apareciesen a la cabeza en $\mathrm{n}$ intervalo de un minuto y medio, frente a las palabras deficiencia y rehabilitación. Las respuestas han sido analizadas con el objetivo de identificar aspectos comunes que permitiesen la creación de categorías para el agrupamiento de los datos. Se han computado las diferencias entre los porcentajes de respuesta del $1^{\circ}$ y $4^{\circ}$ año para cada categoría creada. Se ha verificado que los alumnos del $I^{\circ}$ año han citado características más relacionadas al sentido común, y los del $4^{\circ}$ año han señalado un mayor número de atributos de características técnicocientíficas. Los resultados han sido discutidos en función de la influencia del curso de graduación en los conceptos analizados.

Palabras clave: Conceptos, Rehabilitación; teorías psicológicas 


\section{Introdução}

Espera-se que o aluno, ao término de seu curso de graduação, tenha modificado muitos dos conceitos com os quais ingressou, mormente os referentes a aspectos centrais das diferentes disciplinas cursadas. Muito comumente, ao iniciar seu curso universitário, o aluno ou não tem absolutamente noções sobre diferentes aspectos do conteúdo curricular ou, o que é mais comum, apresenta conceitos inadequados, incompletos, pouco precisos, quando não totalmente errôneos. $\mathrm{Na}$ verdade, um dos objetivos principais dos cursos, freqüentemente expressos em seu programa de estudos, é levar o aluno a aprender novos conceitos ou reformulá-los à luz dos conhecimentos teóricopráticos adquiridos no decorrer de sua graduação universitária. Assim sendo, é razoável afirmar que a efetividade de um curso pode ser aferida ou avaliada pela competência em modificar os conceitos do senso comum dos alunos iniciantes e pela formação de conceitos mais de acordo com os conhecimentos e práticas científicos vivenciados nas diversas disciplinas. Se pudermos avaliar o domínio de diferentes conceitos ao início e final de um programa de estudos, teremos um critério para avaliar a qualidade de ensino ministrada aos alunos. Obviamente, se os graduandos terminarem o curso sem alterarem seus conceitos "ingênuos" ou inadequados, certamente o mesmo não terá cumprido um dos seus principais objetivos.

Normalmente conta-se a centenas os conceitos desenvolvidos durante um curso de graduação. Analisálos todos é uma tarefa inviável e, até mesmo, desnecessária. Todavia, alguns poucos conceitos são tidos como fundamentais ou centrais por especialistas de uma área de conhecimentos. Levar os alunos ao seu completo domínio deve ser o objetivo e a preocupação de todo programa de estudos. Caberia, então, para estes conceitos, e somente para estes, avaliar as mudanças ocorridas no decorrer de uma graduação universitária.

O objetivo deste estudo, de caráter exploratório, foi avaliar as mudanças conceituais dos alunos do primeiro e último anos de um curso de Fisioterapia com referência a dois conceitos fundamentais desta área de conhecimento e atuação prática: DEFICIÊNCIA e REABILITAÇÃO, visando avaliar a ocorrência e o sentido de tais mudanças. A hipótese (e a expectativa) do mesmo é a de que os alunos, ao longo do curso, modifiquem suas noções ingênuas, incorretas e mais ligadas ao senso comum na direção de conceitos sofisticados, precisos e mais ligados ao conhecimento científico.

Antes, todavia, de apresentar a metodologia e os resultados desta pesquisa cabe analisar os conceitos em apreço à luz da bibliografia pertinente.

\section{Conceituação de deficiência e reabilitação}

Até o século XVIII, a deficiência era vista como produção mítica e de ameaça social e, a partir do século XIX, como uma conotação de patologia. Foi somente no século $X X$, de maneira bastante progressiva que a concepção de deficiência foi sendo alterada, deslocando-se o foco do "corpo doente individual" para o do "corpo doente social", fruto da idéia de que as doenças também seriam produtos sociais. Neste sentido, postula-se que os estados de invalidez podem ser influenciados, não apenas por limitações individuais decorrentes da deficiência ou incapacidade, mas também por fatores ambientais e sociais, que variam de acordo com o meio no qual o indivíduo deficiente se acha inserido (Rocha, 1999; 2006).

De acordo com Amiralian e cols. (2000), o modelo médico enfatiza a dependência, enquanto que o modelo social atribui as desvantagens à sociedade, sendo a solução a reestruturação desta. Portanto, segundo esta autora, há a necessidade de se privilegiar um modelo combinado entre os modelos médico e social da deficiência, não se limitando nem aos fatores biológicos, nem aos sociais.

Atualmente, a Organização Mundial da Saúde, com base no CIDDM-2 (Classificação Internacional das Deficiências, Atividades e Participação), define deficiência como:

“(...) uma perda ou anormalidade de uma parte do corpo (estrutura) ou função corporal (fisiológica), incluindo as funções mentais (...) A limitação da 
atividade, antes conceituada como incapacidade, é agora entendida como uma dificuldade no desempenho pessoal. A raiz da incapacidade é a limitação no desempenho da atividade que deriva totalmente da pessoa. No entanto, o termo incapacidade não é mais utilizado porque pode ser tomado como uma desqualificação social. Ampliando o conceito, essa Classificação Internacional inclui a participação, definida como a interação que se estabelece entre a pessoa portadora da deficiência, a limitação da atividade e os fatores do contexto socioambiental” (Ministério da Saúde, 2003, p. 12).

Por sua vez, a Secretaria Municipal de Saúde da Prefeitura Municipal de São Paulo na Proposta da Construção da Política Municipal de Atenção à Pessoa com Deficiência, assim a define:

"Diferença humana que, por suas singularidades, requer atenção a especificidades quanto às formas de comunicação e de mobilidade, de ritmos e estilos de aprendizagem, bem como das maneiras diversas de construir o conhecimento e os relacionamentos sociais.

Fenômeno relacional, social e historicamente construído, apresentando uma perspectiva diferente da concepção tradicional de deficiência, centrada no aspecto de falha na fisiologia humana"(Prefeitura Municipal de São Paulo, 2003, p. 8).

Como fica claro, em tais conceituações, o aspecto social e historicamente construído da deficiência predomina sobre o fisiológico e individual. Atualmente, discute-se que os padrões de normalidade e anormalidade, bem como o estigma e o preconceito, são derivados de interpretações sociais, de modo que a relatividade cultural se torna determinante do tratamento dispensado às pessoas com deficiência.

No tocante ao conceito de reabilitação, também percebemos esta mesma tendência. De acordo como o Ministério da Saúde (1993):

"A reabilitação, enquanto processo, diz respeito ao desenvolvimento das capacidades adaptativas do indivíduo nas diferentes fases de sua vida (...) Implica no desenvolvimento ótimo da pessoa com deficiência, nos seus aspectos funcionais, físicos, psíquicos, educacionais, sociais, profissionais e ocupacionais (...) A reabilitação, enquanto serviço, é um conjunto de atenção à saúde e, portanto, um componente imprescindível da promoção, prevenção e assistência às pessoas, na manutenção de sua saúde e bem estar, bem como de sua família e comunidade (...) é um processo de duração limitada, desenvolvido por equipes interprofissionais de saúde (...) através de ações de diferentes níveis de complexidade. Tem por finalidade que a pessoa deficiente alcance um grau físico, mental, funcional e/ou social ótimo, facilitando o alcance de metas e objetivos de vida estabelecidos por ela naquele momento de sua vida. Os meios para alcançar tal objetivo implicam em medidas que procurem compensar perdas e limitações de funções e outras que buscam facilitar ajustes e reajustes sociais. Assim, as intervenções devem se dar no nível do indivíduo, sua família, comunidade próxima e sociedade em geral"(Brasil, 1993, p. 15).

De forma mais resumida, o Programa de Ação Mundial para Pessoas com Deficiência, da ONU, assim conceitua reabilitação:

\begin{abstract}
"Um processo de duração limitada e com objetivo definido, com vistas a permitir que uma pessoa com deficiência alcance o nível físico, mental e/ou social funcional ótimo, proporcionando-lhe assim os meios de modificar a sua própria vida. Pode compreender medidas com vistas a compensar a perda de uma função ou uma limitação funcional (por exemplo, ajudas técnicas) e outras medidas de facilitar ajustes e reajustes sociais" (p. 38, Ministério da Saúde, 2003).
\end{abstract}

Como se pode depreender das citações apresentadas, em ambos os conceitos, as caracterizações salientam aspectos sociais, ambientais e multidisciplinares tanto do indivíduo portador de deficiência, quanto do processo de reabilitação. Será que os nossos sujeitos estarão atentos para tais 
aspectos? Antes, todavia, de responder a esta questão é necessário definir o que se entende por conceitos neste trabalho.

Ainda que não exista unanimidade entre os psicólogos a respeito da definição de conceito, existe uma razoável concordância entre eles de que o termo refere-se ou designa representações mentais, constituindo-se num tipo de agrupamento cognitivo que possibilita a identificação da enorme variedade e multiplicidade das coisas do mundo. As discrepâncias ou divergências ocorrem quando se procura estabelecer que formas tomam essas representações (para uma descrição mais aprofundada das teorias de conceitos, consultar Lomônaco, 1997). A seguir, serão brevemente apresentadas três destas teorias ou visões como têm sido tradicionalmente nomeadas - $a$ visão clássica, a visão prototípica e a visão teórica - por ordem de seu aparecimento cronológico, dando-se maior destaque a mais recente delas, de acordo com a qual os dados do presente trabalho serão analisados e interpretados.

\section{Teorias de conceitos}

A idéia central da visão clássica é a suposição de que os conceitos são formados pela abstração de atributos comuns a todos os membros de um conjunto de coisas. Por meio do isolamento dos atributos comuns o sujeito forma uma representação que é o próprio conceito. Ao conjunto de coisas abrangidas pelo conceito dá-se o nome de categoria. Por exemplo, pelo fato de entrarmos em contato com uma grande diversidade e variedade de seres vivos, vamos gradualmente percebendo similaridades e diferenças entre eles. Em função de tais similaridades ou atributos comuns, criam-se representações mentais que irão se constituir em conceitos tais como animais, vegetais, cães, gatos, papagaios, árvores, flores, bactérias etc.

Embora esta pressuposição da existência de atributos singularmente necessários e conjuntamente suficientes para definir um conceito tenha sido aceita durante séculos na Filosofia e dezenas de anos na Psicologia, ela passou a ser seriamente questionada a partir de 1970. No dizer de Smith e Medin ( I98I), o problema crucial da visão clássica é o de que décadas de análises realizadas por filósofos, lingüistas e psicólogos e outros especialistas não conseguiram especificar os atributos definidores da maioria dos conceitos.

Diante desta e de outras inadequações que colocam a visão clássica em sérias dificuldades, desenvolveu-se a partir da década de 70 do século passado uma nova maneira de ver os conceitos que veio a ser conhecida como visão prototípica.

Segundo esta teoria, não é a existência de atributos comuns, mas a freqüência com a qual os atributos se repetem entre os membros do que virá a ser uma categoria que determina a formação de conceitos. Depois de repetidos contatos, o sujeito abstrai aqueles que ocorrem mais freqüentemente e, a partir destes elementos, forma uma representação mental, denominada protótipo, que passa então a representar a categoria. A suposição central à visão prototípica é a de que os atributos ou características não se distribuem de forma aleatória no mundo real, mas apresentam-se correlacionados. Assim, por exemplo, a presença de bicos e penas em aves é mais comum do que a de pelos e bocas. Conseqüentemente, na formação do protótipo de ave, os dois primeiros atributos terão precedência sobre os dois últimos. Uma vez formados os protótipos, o sujeito deles se utiliza para decidir pela inclusão ou exclusão de novos membros na categoria. Se um novo tipo de ave que o sujeito nunca viu for semelhante ao protótipo armazenado em sua memória, o sujeito não terá dúvidas em incluí-lo na categoria. Se for muito diferente, ele ficará em dúvida quanto a sua inclusão e poderá, até mesmo, excluí-lo da categoria, erroneamente..

Desta forma, a visão prototípica substitui a noção de atributos definidores pela de atributos característicos. Entende-se por característicos aqueles atributos que têm maior probabilidade de ocorrer nos exemplos dos conceitos. Ao fazê-lo, rejeita a noção fundamental da visão clássica e se apresenta como uma alternativa teórica para explicar a formação de conceitos, mormente os denominados conceitos naturais.

Em face de sua capacidade de responder a muitas das questões que afligem a visão clássica, a abordagem prototípica gozou de alguma popularidade entre os 
estudiosos do processo de formação de conceitos nas décadas de 70 e 80 do século passado. Cedo, porém revelaram-se algumas de suas limitações. A principal delas, segundo Murphy e Medin (1985), é a de que esta teoria não estabelece restrições sobre quais atributos devem fazer parte do conceito, admitindo a inclusão de uma grande variedade de características na sua representação o que, na prática, o tornaria muito pouco significativo. Por exemplo, é perfeitamente possível arrolar um grande número de características comuns a coisas que no mundo real são diferentemente categorizadas, tais como computador e estetoscópio. Ambos são objetos concretos, ocupam lugar no espaço, são úteis, custam dinheiro, não existiam na Idade Média, foram inventados pelo ser humano, possuem metais em sua constituição etc. Não obstante a ocorrência de tantos aspectos compartilhados, eles são diferentemente categorizados em nossa cultura, mostrando que não basta à existência de atributos comuns para a criação de categorias.

Como se pode depreender, nas duas teorias de conceitos consideradas - a visão clássica e a visão prototípica - o fator similaridade exerce um papel importante, até mesmo fundamental, na explicação da formação de conceitos. Na visão clássica, a similaridade diz respeito ao compartilhamento de atributos comuns pelos membros de uma categoria. $\mathrm{Na}$ prototípica, à similaridade dos exemplos, a um protótipo ou representação mental. Entretanto, o papel da similaridade como elemento responsável pela criação de categorias passou a ser seriamente questionado a partir da publicação, em 1985, de um importante artigo de autoria de Murphy e Medin. A crítica maior a esta variável é a de que a noção de similaridade não é suficientemente restritiva para explicar a formação de conceitos. No dizer dos autores: "A similaridade é uma noção muito intuitiva. Infelizmente, ela é ainda mais ilusória do que intuitiva. Um problema em utilizar a similaridade para definir categorias é o de que a similaridade é flexível demais" (p. 1473). Ou seja, sem claras restrições sobre o que deve ser considerado como similar quaisquer dois objetos podem ser considerados similares em vários aspectos, como visto anteriormente nos exemplos de computador e estetoscópio. Se não é a similaridade a responsável pela criação de categorias, a que fator devemos atribuir a formação de nossos conceitos?

Esta e outras dificuldades que não serão aqui consideradas criaram condições para o aparecimento de uma nova abordagem ao processo de formação de conceitos, fundamentada não mais na similaridade, mas focalizada sobre o conhecimento das pessoas a respeito do mundo, que veio a ser denominada de visão teórica.

Keil (1989), um dos mais importantes estudiosos e pesquisadores da visão teórica salienta, logo no início de seu livro sobre a mesma, o aspecto fundamental desta teoria. Segundo ele: “(...) conceitos são construídos como tipos de coisas intrinsecamente relacionais. Eles não são entidades isoladas, conectadas apenas a serviços de proposições. Nenhum conceito individual pode ser compreendido sem algum entendimento de como ele se relaciona a outros conceitos" (p.l). Ou seja, cada conceito é concebido não mais isoladamente, mas como parte de uma rede de relações com outros conceitos da qual deriva seu significado.

Esta rede de relações é denominada teoria. $\mathrm{O}$ termo, todavia, não se refere unicamente (nem predominantemente) a teorias científicas, mas principalmente ao nosso conhecimento do mundo, por mais ingênuo que este seja. Um exemplo de Oliveira (1994) ajuda a esclarecer o significado que o termo teoria assume nesta visão de conceitos. Diznos ele: no que diz respeito a animais, as pessoas, mesmo sem qualquer instrução formal, sabem que os animais nascem, crescem e morrem; que se alimentam; que produzem filhos da mesma espécie etc. A este tipo de conhecimento aplica-se o termo ingênuo. Ou seja, as informações anteriormente consideradas e suas relações constituiriam uma biologia ingênua. Da mesma forma, podemos identificar rede de relações em outras áreas do conhecimento, dando origem a uma física ingênua, a uma psicologia ingênua, a uma cosmologia ingênua etc.

A visão teórica, pois, acredita que o agrupamento de diferentes membros numa mesma categoria deve-se, não ao fator similaridade, mas a uma teoria comum que os mantém unidos, formando uma estrutura internamente coerente. A esta rede de conexões, Keil 
(1989) denomina homeostase causal, significando com esta expressão que a estrutura se mantém em equilíbrio em face das relações causais existentes entre os conceitos que constituem a rede. A homeostase causal implica que este equilíbrio pode ser abalado pela aprendizagem de uma nova informação capaz de rompê-lo, dando origem a uma reorganização da estrutura conceitual. Desta forma, a rede de interconexões entre os conceitos (ou seja, a teoria) vem a sofrer mudanças e a se transformar no decorrer de novas aprendizagens.

No presente estudo, trabalhamos com a hipótese de que as informações que os graduandos de Fisioterapia recebem ao longo do curso nas diferentes disciplinas, juntamente com suas vivências no atendimento de pacientes, deverão provocar alterações ou mudanças nos seus conceitos de deficiência e reabilitação ou, mais especificamente, na rede conceitual na qual este conceito está inserido.

\section{Método}

\section{Participantes}

Participaram da amostra, 67 alunos do primeiro e quarto anos do curso de graduação em Fisioterapia, de uma universidade particular do estado de São Paulo, sendo 18 do sexo masculino e 49 do feminino, 27 do primeiro ano e 40 do quarto ano.

\section{Material}

Cada aluno utilizou um bloco de papel com três páginas (três metades de folha de papel sulfite, tamanho A4). Na parte superior da primeira folha, o aluno deveria informar alguns dados pessoais (nome, sexo e série escolar); na parte inferior estavam impressas as seguintes instruções:

Estamos interessados em conhecer as idéias comumente atribuídas aos termos "Deficiência" e "Reabilitação", pelos estudantes de Fisioterapia. Assim sendo, venho solicitar sua colaboração neste trabalho de pesquisa.

Na parte superior das duas páginas seguintes, você encontrará as palavras DEFICIÊNCIA e REABILITAÇÃO. $O$ que lhe pedimos é muito simples: leia o primeiro termo e, a seguir, no período de um minuto e meio, escreva no espaço em branco todas as características que the vierem à mente diante deste estímulo. A sua primeira impressão é muito importante; portanto, você não deve se preocupar em saber se suas respostas estão adequadas ou não. $O$ que nos interessa são suas evocações ou associações, diante do estímulo apresentado.

Proceda da mesma maneira na página seguinte, ou seja, sem se preocupar com a maneira pela qual você respondeu à página anterior!

Muito obrigado pela sua colaboração.

Como salientado nas instruções, na parte superior das páginas 2 e 3, respectivamente, estavam impressas em letras maiúsculas as palavras DEFICIÊNCIA E REABILITAÇÃO. Todo o restante destas páginas estava em branco.

Muito embora o instrumento utilizado tenha sido originalmente concebido por adeptos da visão prototípica, ele também se presta à análise de dados coletados sob outras concepções teóricas. Neste trabalho, em face da opção dos pesquisadores pela visão teórica, os dados foram analisados e interpretados de acordo com esta teoria de conceitos.

\section{Procedimento}

A coleta de dados foi realizada no curso de graduação em Fisioterapia de uma universidade particular do estado de São Paulo. O período de aplicação do instrumento de pesquisa situou-se entre outubro e novembro de 2003, após o consentimento da Coordenadoria do curso.

A aplicação do instrumento foi feita em sala de aula por uma das pesquisadoras. Os sujeitos foram informados a respeito dos objetivos da pesquisa e lhes foi solicitado sua participação voluntária. Nenhum dos sujeitos se recusou a colaborar.

As instruções da primeira página então foram lidas, então, as instruções da primeira página. Após esta leitura, as duvidas dos alunos foram sanadas e os dados pessoais informados. Passou-se, em seguida, à tarefa de escrever, no período de 90 segundos, as associações evocadas pela palavra DEFICIÊNCIA. Findo este intervalo de tempo, a pesquisadora solicitou aos sujeitos que virassem a folha e repetissem o procedimento diante do termo REABILITAÇÃO. Terminada a aplicação, as folhas foram recolhidas. 


\section{Resultados}

A partir dos protocolos, todas as respostas dos sujeitos às palavras "deficiência" e "reabilitação" foram digitadas e organizadas por ordem alfabética, separadamente para o primeiro e quarto anos. As listas de respostas foram, então, lidas diversas vezes pelos pesquisadores, no intuito de identificar aspectos comuns que permitissem a criação de categorias para agrupamento dos dados. A formação das categorias foi discutida pelos três pesquisadores, que procuraram chegar a um consenso sobre quais itens deveriam ou não ser incluídos em cada categoria, assim como quais itens não pertenciam a nenhuma das categorias elaboradas e deveriam ser agrupados na categoria "Outras respostas".

Adotou-se como critério de criação da categoria o fato desta englobar, no mínimo, $5 \%$ do total de respostas dos alunos do primeiro ou do quarto ano. Procurou-se, assim, eliminar respostas idiossincráticas e/ou com número muito pequeno de citações. Todavia, quando uma categoria era criada para uma das séries escolares, ela era obrigatoriamente criada para a outra série também, a fim de possibilitar a comparação entre elas.

As categorias elaboradas e uma breve descrição do seu significado são apresentadas a seguir:

\section{DEFICIÊNCIA}

Dificuldade / Incapacidade / Dependência: engloba termos referentes a aspectos gerais da deficiência, indicativos de falta, redução, limitação e dependência de outras pessoas (exemplos: "falta", "ausência", "redução", “impossibilidade”, “dependente”, "precisa de alguém”).

Afastamento da Normalidade: abrange atributos indicativos de que o indivíduo foge dos padrões de normalidade ou que expressam comparações com a maneira de ser da maioria das pessoas (exemplos: "anormalidade", "diferencia do normal”, "algo não adequado").

Atividades Funcionais e da Vida Diária: referente a termos que mencionam qualquer impossibilidade de realização de tarefas cotidianas ou atividades de vida diária (exemplos: "fazer algo", "funções”, "atividades”, "tarefa”). Causas da Deficiência: inclui palavras relacionadas às origens ou aos fatores causadores da lesão ou doença específica (exemplos: "câncer", "trauma").

Implicações Motoras: refere-se a termos indicativos de dificuldades para a realização de movimentos e/ou prejuízo das funções motoras (exemplos: "andar”, "coordenação").

Emoções Negativas: abrange atributos que expressam aspectos emocionais negativos que se supõe sejam característicos da pessoa com deficiência ou sejam evocados nas outras pessoas, ou nos próprios alunos, quando se deparam com alguém deficiente (exemplos: “medo”, “depressão”, “angústia”, “tristeza”).

Necessidade de Apoio Emocional: agrupa termos indicativos da necessidade de apoio emocional ou qualidades necessárias para superar a deficiência (exemplos: "incentivo”, "confiança”, "adaptação", "perseverança”).

Exclusão Social / Preconceito: engloba atributos indicativos do prejuízo causado pela deficiência, referentes ao relacionamento e à exclusão social (exemplos: "exclusão social", "preconceito", "falta de oportunidade").

Outras Respostas: qualquer outro tipo de resposta não classificada nas categorias criadas.

\section{REABILITAÇÃO}

Recuperação / Reaprendizagem: engloba termos referentes aos processos por meio dos quais se procura recuperar algo que foi perdido (exemplos: "devolução", "recomeço", "reeducar", "reaprender").

Ajuda / Promoção / Tratamento: quando a reabilitação foi vista em termos do tratamento aplicado, tendo o terapeuta para isso um papel ativo (exemplos: "promover", "facilitar", "dar condições”, "amenizar”, “ajudar”).

Participantes da Reabilitação: incluem citações de pessoas envolvidas no processo de reabilitação, tanto profissionais quanto membros da família 
(exemplos: "Fisioterapia", "outros profissionais", "família").

Conseqüências Funcionais da Reabilitação: agrupa termos relativos recuperação da capacidade de realizar tarefas cotidianas/AVD's (exemplos: "volta às atividades", "independência", "desde que seja funcional").

Retorno à Normalidade: engloba termos que mencionam a reabilitação como um processo de retorno à ou aproximação da normalidade (exemplos: "voltar ao normal", "aproximar-se das condições normais").

Melhoria da Qualidade de Vida: respostas referentes à promoção da qualidade de vida e aos sentimentos positivos resultantes do processo de reabilitação (exemplos: "bem estar", "qualidade de vida", "condições de vida", "renascimento", "felicidade").

Necessidades Emocionais: inclui termos que dizem respeito a necessidades e qualidades emocionais que se supõem necessárias para o processo de reabilitação (exemplos: "autoajuda", "autoconfiança”, "vontade”, "aceitação", "esperança”, "calor-humano").

Reintegração à Sociedade: respostas referentes à inclusão social ou retorno à sociedade (exemplos: "introduzir ao meio", "reintegrar", “inclusão”).

Outras Respostas: respostas não englobadas nas categorias criadas.
Elaboradas as categorias, elas foram utilizadas para agrupar as respostas dos sujeitos e para computar as freqüências absoluta e percentual de cada uma das categorias criadas para "deficiência" e "reabilitação".

Os valores percentuais do primeiro e quarto anos, bem como as diferenças entre eles são apresentadas na Tabela I, para "deficiência", e na Tabela 2, para "reabilitação". Os valores constantes da coluna "diferença", quando negativos, indicam maior porcentagem de ocorrência no $4^{\circ}$ ano; quando positivos, a ocorrência maior foi no $1^{\circ}$ ano.

Como se pode observar na Tabela I, as maiores porcentagens de respostas ocorreram na categoria Dificuldade / Incapacidade / Dependência. Esta categoria refere-se a aspectos gerais da deficiência, indicando ausência, limitação e/ou dependência de outras pessoas. Foi também nesta categoria que ocorreu a maior diferença entre os grupos (-14,6\%), com uma concentração maior de respostas no $4^{\circ}$ ano. Uma outra diferença marcante ocorreu na categoria Exclusão Social / Preconceito (I I,27\%), na qual o número de respostas dos alunos do $1^{\circ}$ ano foi quase quatro vezes maior que o do $4^{\circ}$ ano. $O$ inverso ocorreu com a categoria Atividades Funcionais e da Vida Diária, na qual o número de respostas foi sensivelmente maior no $4^{\circ}$ ano, acusando uma diferença de $-10,62 \%$. Nas demais categorias, à exceção de Outras Respostas, a diferença entre os grupos foi menor, variando entre I,27\% e $6,19 \%$, indicando uma maior concordância entre os sujeitos de ambos os grupos.

Tabela I. Reabilitação: porcentagem de respostas e diferença em cada uma das categorias

\begin{tabular}{lrrr}
\hline \multirow{2}{*}{ Categorias } & \multicolumn{2}{c}{ Porcentagem } & \multirow{2}{*}{ Diferença } \\
\cline { 2 - 3 } & $1^{\circ}$ ano & $4^{\circ}$ ano & \\
\hline Recuperação / Reaprendizagem & 7,14 & 26,67 & $-19,53 \%$ \\
Ajuda / Promoção / Tratamento & 7,14 & 10,67 & $-3,53 \%$ \\
Participantes da Reabilitação & 7,14 & 0,00 & $7,14 \%$ \\
Conseqüências Funcionais da Reabilitação & 4,28 & 18,67 & $-14,39 \%$ \\
Retorno à Normalidade & 1,43 & 5,33 & $-3,9 \%$ \\
Melhoria da Qualidade de Vida & 10,00 & 16,00 & $-6 \%$ \\
Necessidades Emocionais & 30,00 & 4,00 & $26 \%$ \\
Reintegração à Sociedade & 15,71 & 2,67 & $13,04 \%$ \\
Outras Respostas & 17,14 & 16,00 & $1,14 \%$ \\
\hline
\end{tabular}


Tabela 2. Reabilitação: porcentagem de respostas e diferença em cada uma das categorias

\begin{tabular}{lcrr}
\hline \multirow{2}{*}{ Categorias } & \multicolumn{2}{c}{ Porcentagem } & \multirow{2}{*}{ Diferença } \\
\cline { 2 - 3 } & $1^{\circ}$ ano & $4^{\circ}$ ano & \\
\hline Recuperação / Reaprendizagem & 7,14 & 26,67 & $-19,53 \%$ \\
Ajuda / Promoção / Tratamento & 7,14 & 10,67 & $-3,53 \%$ \\
Participantes da Reabilitação & 7,14 & 0,00 & $7,14 \%$ \\
Conseqüências Funcionais da Reabilitação & 4,28 & 18,67 & $-14,39 \%$ \\
Retorno à Normalidade & 1,43 & 5,33 & $-3,9 \%$ \\
Melhoria da Qualidade de Vida & 10,00 & 16,00 & $-6 \%$ \\
Necessidades Emocionais & 30,00 & 4,00 & $26 \%$ \\
Reintegração à Sociedade & 15,71 & 2,67 & $13,04 \%$ \\
Outras Respostas & 17,14 & 16,00 & $1,14 \%$ \\
\hline
\end{tabular}

Comparando-se os dados da Tabela I com os da Tabela 2, pode-se constatar que as diferenças entre os grupos foram maiores no conceito de "reabilitação" do que no conceito de "deficiência". A maior delas ocorreu na categoria Necessidades Emocionais (26\%), com uma alta concentração de respostas no $I^{\circ}$ ano e um número muito pequeno no $4^{\circ}$ ano. A segunda categoria com a maior diferença percentual foi Recuperação / Reaprendizagem (-19,53\%), com uma maior concentração de respostas nos alunos do $4^{\circ}$ ano. Conseqüências Funcionais da Reabilitação e Reintegração à Sociedade também apresentaram diferenças significativas (-14,39\% e 13,04\%, respectivamente). Nas demais categorias, com exceção de Outras Respostas, as diferenças percentuais foram menores, variando entre $-3,53 \%$ e $7,14 \%$.

Os dados de freqüência absoluta foram utilizados na análise estatística dos resultados. Para tal análise foi empregada a estatística do qui-quadrado $\left(\chi^{2}\right)$ para uma amostra, uma vez que os dados do $1^{\circ}$ e do $4^{\circ}$ anos foram considerados separadamente. Esta prova é adequada para analisar situações em que os dados são agrupados em duas ou mais categorias e permite comprovar se existe diferença significante entre o número observado de respostas em determinada categoria e o respectivo número esperado, baseado na hipótese de nulidade (Siegel, 198I).

Os valores de $\chi^{2}$ encontrados para o conceito de "deficiência", tanto para o primeiro ( $\mathrm{n}=70$; g.l. $=8 ; \chi^{2}$ crítico $=20,09 ; \chi^{2}$ observado $=22,33 ; \mathrm{p}$
$<0,0$ I) quanto para $\circ$ quarto anos $(\mathrm{n}=90$; g.l. $=$ $8 ; \chi^{2}$ crítico $=20,09 ; \chi^{2}$ observado $=85,6 ; \mathrm{p}<$ $0,0 \mathrm{I}$ ), indicam que as diferenças entre as freqüências das categorias foram altamente significantes, rejeitando a hipótese nula.

O mesmo ocorreu com o conceito de "reabilitação", tanto para o primeiro $(\mathrm{n}=70$; g.l. $=$ 8; $\chi^{2}$ crítico $=20,09 ; \chi^{2}$ observado $=38,03 ; \mathrm{p}<$ $0,0 \mathrm{I})$ quanto para o quarto anos $\left(\mathrm{n}=75 ; \mathrm{g} . \mathrm{l}\right.$. $=7 ; \boldsymbol{\chi}^{2}$ crítico $=18,48 ; \boldsymbol{\chi}^{2}$ observado $\left.=29,22 ; \mathrm{p}<0,0 \mathrm{I}\right)$, rejeitando igualmente a hipótese nula com alto grau de significância.

\section{Discussão}

A discussão dos dados será realizada em duas etapas. Na primeira, serão consideradas as diferenças encontradas entre os dois grupos de sujeitos (do primeiro e do quarto anos), em ambos os conceitos estudados, buscando explicar tais diferenças com base na literatura e/ou no conhecimento e na vivência das duas autoras com cursos de graduação na área da reabilitação (Fisioterapia e Terapia Ocupacional). Numa segunda etapa, procurar-se-á verificar se as categorias criadas apresentam alguma coerência interna entre elas, ou seja, se podemos identificar no conjunto em apreço o fenômeno que Keil (1989) denomina de homeostase causal, tal como definido na introdução deste trabalho. 
Para o conceito de deficiência, verifica-se que a categoria Dificuldade / incapacidade / dependência aglutinou o maior número de respostas em ambos os grupos $(24,28 \%$ e $38,88 \%$, respectivamente), com uma diferença de $14,6 \%$ entre o primeiro e o último ano. Uma vez que muitos atributos por ela abarcados estão ligados a idéias do senso comum, que apresentam o deficiente como uma pessoa limitada, incapacitada e necessitada de ajuda, seria de se esperar uma maior prevalência deste tipo de respostas no $1^{\circ}$ ano. Todavia, os alunos do $4^{\circ}$ ano apresentaram o maior número de respostas nesta categoria, demonstrando a permanência do estereótipo do deficiente como um indivíduo bastante dependente do auxílio dos outros para sua sobrevivência.

Como explicar a permanência do estereótipo após os quatro anos do curso? Uma possível explicação ou, pelo menos, parte da explicação, pode estar na formação predominantemente médica recebida pelos alunos de Fisioterapia, na qual é dada uma grande ênfase a aspectos tais como lesões, limitações físicas / funcionais e dificuldades da pessoa deficiente ao invés de voltar-se para suas capacidades e potencialidades. No entender dos autores, ao ver enfatizada repetidamente, a figura do deficiente como a de um indivíduo lesado, prejudicado, incapacitado, o aluno de Fisioterapia pode introjetar esta imagem e perpetuá-la em sua futura prática profissional, o que é bastante lamentável, pois só contribui para manutenção de um estereótipo que se quer modificar.

A categoria Exclusão social/preconceito abarcou a segunda maior concentração de respostas do $1^{\circ}$ ano (I5,7I\%), com uma diferença de II,27\% quando comparadas às do $4^{\circ}$ ano, mostrando uma diminuição da importância dessa característica ao término do curso (apenas $4,44 \%$ de respostas). O que significa este dado? Será que o formando não vê o deficiente como alguém que é objeto de preconceito e, por conseqüência, sofre um processo de exclusão social? Uma possível hipótese é a de que o aluno no final do curso já alterou seu conceito de senso comum a respeito do indivíduo deficiente, isto é, como o de alguém excluído e alvo de preconceito da sociedade, para o de alguém passível de inclusão social por meio do processo de reabilitação. Ou seja, uma mudança bastante desejável. Todavia, os dados referentes à categoria reintegração à sociedade no estudo do conceito de reabilitação parecem contraditar esta hipótese, uma vez que registram um percentual de respostas muito baixo no $4^{\circ}$ ano (apenas 2,67\%), parecendo evidenciar um grande descaso desses alunos para com o mecanismo de inclusão social. Como explicar este lamentável descaso? Uma explicação completa deste resultado é bastante difícil para os pesquisadores/autores deste trabalho que não conhecem a fundo a instituição de onde os dados foram coletados. É possível hipotetizar, todavia, que isto possa ter ocorrido pela não consideração das implicações sociais da deficiência durante o curso de graduação. Desta forma, o fisioterapeuta em processo de formação poderá se dar por satisfeito em realizar com proficiência suas atividades técnicas no processo de reabilitação, acreditando que mais não lhe cabe fazer, pois, ao executar suas tarefas com competência, ele estará indiretamente preparando o paciente para o processo de reintegração à sociedade. Embora esta possa ser uma posição defensável e, até mesmo compreensível, é de se estranhar que tal aspecto tenha causado mais preocupações aos alunos do $1^{\circ}$ do que aos do $4^{\circ}$ ano uma vez que é sobejamente reconhecidas a existência de preconceitos e a exclusão de pessoas com deficiência às escolas regulares, ao mercado de trabalho e às atividades comunitárias. Seria de se esperar, portanto, que este atributo tivesse uma ocorrência significativa no $1^{\circ}$ ano (tal como de fato ocorreu) e mais forte ainda no $4^{\circ}$ ano, uma vez que a inclusão social pode ser considerada um dos maiores objetivos do processo de reabilitação efetuado pelos profissionais de saúde, dentre os quais se inclui o fisioterapeuta. Para Moraes (2004), é preciso que o fisioterapeuta tenha claro que o processo de reabilitação deve ser direcionado para a inclusão escolar e social da pessoa com deficiência física e não apenas para a recuperação de suas funções motoras. Neste sentido, esta autora propõe a criação de uma disciplina sobre a inclusão escolar de crianças com deficiência física, nos cursos de graduação em fisioterapia.

Em contrapartida a esta reduzida preocupação com os aspectos sociais da deficiência pelos alunos do 
último ano, verifica-se uma maior atenção para com os aspectos técnico-científicos da deficiência, tal como pode ser constatada nas categorias Atividade funcional e da vida diária ( $17,77 \%$, com uma diferença de $10,63 \%$ em relação ao $1^{\circ}$ ano) e Implicações motoras (13,33\%, com diferença de $-6,19 \%)$ que constituem grandes demandas da reabilitação. Portanto, um resultado perfeitamente esperável que não necessita de maiores considerações.

A categoria Afastamento da normalidade apresentou uma diminuição no número de respostas de $3,83 \%$ do $1^{\circ}$ para $\circ 4^{\circ}$ ano, o que está de acordo com a tendência atual de não comparar o indivíduo com deficiência com padrões de normalidade da pessoa não-deficiente, sendo as deficiências consideradas como diferenças humanas singulares (Prefeitura Municipal de São Paulo, 2003). Curiosamente, porém, no conceito de reabilitação, ocorreu um movimento inverso, ou seja, um aumento de $3,9 \%$ do $1^{\circ}$ para $\circ 4^{\circ}$ ano na categoria Retorno à normalidade. Considerando-se, todavia, que a diferença percentual é bastante pequena e variou em ambos os sentidos, podemos pensar em flutuações numéricas aleatórias que não comprometem o resultado. Parece mais adequado salientar que as duas categorias englobaram um número relativamente reduzido de respostas em ambas as turmas, indicando uma pequena preocupação dos sujeitos com a comparação normalidade/anormalidade.

A categoria Emoções negativas agrupou $8,57 \%$ das respostas do $1^{\circ}$ ano, ocorrendo uma diminuição de 3,02\% ao longo de todo o curso de graduação. Este aspecto pode ser considerado positivo uma vez que esta categoria engloba termos referentes ao impacto negativo que a deficiência provoca no aluno ao se defrontar com o paciente ("medo", "angústia"). $\mathrm{Na}$ opinião dos autores, este é um resultado previsível e desejável, uma vez que se espera que o futuro fisioterapeuta vá se acostumando, no decorrer de sua formação profissional, com as múltiplas e variadas manifestações de deficiência e responda a elas sem a vivência de emoções negativas. $O$ mesmo, todavia, não se pode afirmar a respeito da categoria Necessidade de apoio emocional na qual observa-se um pequeno percentual de respostas em ambos os grupos $(5,7$ I $\%$ no primeiro ano e $3,33 \%$ no quarto ano, com uma pequena diferença entre eles), o que parece indicar a despreocupação dos alunos com esta possível conseqüência da deficiência. Esta desconsideração dos atributos emocionais gerados pela deficiência pode ser considerada indesejável, uma vez que negligencia o fato de que a deficiência ou a incapacidade de realizar algo vem freqüentemente envolvida em implicações emocionais e a desconsideração deste aspecto pode resultar até mesmo no fracasso do tratamento.

Quanto ao conceito de reabilitação, a categoria que apresentou a maior concentração de respostas no $1^{\circ}$ ano e a maior diferença entre os grupos foi Necessidades emocionais (com $30 \%$ das respostas do $1^{\circ}$ ano e uma diferença de $26 \%$ quando comparada com $\circ 4^{\circ}$ ano). Este dado indica claramente que as características relacionadas às necessidades emocionais do paciente deficiente no processo de reabilitação estão bastante vinculadas ao senso comum, que associa o sucesso do processo de reabilitação com qualidades e/ou estados emocionais positivos do paciente, tais como autoconfiança, esperança, vontade, auto-ajuda etc. A diminuição de respostas do $1^{\circ}$ para $\circ 4^{\circ}$ ano era esperada e pode ser considerada como um aspecto positivo, uma vez que, por um lado, deixa de atribuir ao paciente a exclusiva responsabilidade pelo seu progresso no tratamento e, por outro lado, enfatiza a efetividade das técnicas fisioterapêuticas no processo de reabilitação. Todavia, o valor da diferença surpreende pela sua magnitude $(26 \%)$. Neste aspecto ele pode ser objeto de preocupação, pois reflete uma exagerada desconsideração para com os fatores emocionais envolvidos no processo de reabilitação, fatores estes importantes em todo o processo de recuperação da saúde de pacientes, deficientes ou não. De acordo com Pontes (2002) e Moraes (2004), a formação do fisioterapeuta deve ser mais humanitária, voltada não unicamente para $\circ$ tratamento da enfermidade, mas também para o paciente como um ser humano. Para essas autoras, não basta a aprendizagem de técnicas de tratamento da estrutura lesada, também é necessário aprender a olhar o paciente como um todo.

A categoria Recuperação/reaprendizagem apresentou a maior incidência de atributos evocados no $4^{\circ}$ ano $(26,67 \%$ das respostas) e uma grande 
diferença de $-19,53 \%$ quando comparada ao $1^{\circ}$ ano. De modo similar, a categoria Conseqüências funcionais da reabilitação agrupou $18,67 \%$ das respostas do $4^{\circ}$ ano, com uma diferença de $-14,39 \%$ em relação ao $1^{\circ}$ ano. Tal resultado indica uma forte associação entre - processo de reabilitação e a recuperação de capacidades perdidas ou severamente prejudicadas. Pode-se afirmar que tal resultado está perfeitamente de acordo com as expectativas, uma vez que ele reflete a aprendizagem dos objetivos do processo de recuperação, qual seja, devolver ao paciente, pelo menos, uma parte de suas capacidades perdidas e habilitá-lo a realizar as atividades da vida diária com o máximo de eficiência possível (Brasil, 1993; Ministério da Saúde, 2003).

Melhoria da qualidade de vida apresentou a terceira maior incidência, tanto para $\circ 1^{\circ}(10 \%)$ quanto para - $4^{\circ}$ ano (16\%), mostrando que as conseqüências positivas do processo de reabilitação são percebidas desde o início da graduação e só tendem a aumentar no decorrer dos anos de curso. Ajuda / promoção / tratamento também obteve um aumento no número de respostas do $1^{\circ}$ para $\circ 4^{\circ}$ ano (diferença de $3,53 \%$ ), o que mostra uma maior atenção ao processo de reabilitação em si e ao papel ativo do terapeuta como promotor e facilitador do tratamento reabilitacional, sem considerar, porém, que o indivíduo em tratamento também deve ter um papel ativo, principalmente na escolha dos objetivos do tratamento.

Como anteriormente comentada Reintegração à sociedade, agrupou $15,71 \%$ das respostas do $1^{\circ}$ ano e apenas $2,67 \%$ das respostas do $4^{\circ}$ ano, apresentando umas das maiores diferenças entre os grupos (I3,04\%). As possíveis razões para tal resultado já foram assinaladas anteriormente.

De maneira geral, a partir da análise dos resultados, pode-se perceber, pelo menos, uma tendência geral dos dados, qual seja, enquanto os alunos do primeiro ano parecem enfatizar os aspectos emocionais e sociais da deficiência e do processo de reabilitação, os do $4^{\circ}$ ano focalizaram mais os atributos referentes aos aspectos motores e funcionais de ambos os conceitos, indicando ter havido uma reformulação das idéias do senso comum em direção a uma outra ligada a conhecimentos e práticas vivenciadas ao longo do curso, conforme, aliás, esperado e hipotetizado no início da pesquisa.

Se considerarmos, porém, que as definições mais atuais de deficiência tendem a atribuir maior atenção às implicações sociais da deficiência, vista como um fenômeno relacional e socialmente construído, a partir de atividades e interações sociais, e o processo de reabilitação não sendo focado apenas na pessoa portadora de deficiência, mas também no ambiente familiar, comunitário e social que poderemos perceber que as respostas dos alunos do $4^{\circ}$ ano parecem ir contra estas concepções mais modernas dos conceitos estudados, ou seja, há um deslocamento do social para o individual, no decorrer do curso de graduação, contrariamente à tendência atual, de deslocamento do individual para o social.

Uma vez que a atuação do profissional de fisioterapia está mais voltada para aspectos individuais, é bastante compreensível que isto se reflita nas respostas dos alunos, mormente os do último ano. É conveniente ressaltar, todavia, a importância de conhecer e considerar as demais necessidades das pessoas com deficiência que passam por tratamento reabilitacional, a fim de que estas sejam vistas como um todo e que suas reais necessidades sejam adequadamente consideradas, ainda que por outros profissionais da saúde.

Tal prevalência do individualismo também se reflete nas respostas dadas à categoria Participantes da reabilitação, que não apresentou nenhuma resposta no $4^{\circ}$ ano. Não obstante a reabilitação, tal como definida pelo Ministério da Saúde (1993), seja considerada como um processo a ser desenvolvido por equipes interdisciplinares, este aspecto parece não ter sido suficientemente enfatizado durante a graduação, levando à idéia inadequada de que o processo de reabilitação pode ser integralmente realizado pelo fisioterapeuta. $\mathrm{Na}$ verdade, segundo Trelha e Santos (2003), o aluno de fisioterapia deveria ter contato desde o início de sua formação com o trabalho em equipe, para que possa perceber a importância da interdisciplinaridade na reabilitação do paciente.

Uma vez discutidas as diferenças entre os grupos e sugeridas algumas hipóteses para explicá-las, passar- 
se-á agora a analisar os dados a fim de verificar se eles apresentam coerência interna, ou seja, se o fenômeno que Keil (1989) denomina de homeostase causal pode ser detectado neste estudo. Como considerado na introdução, a visão teórica pressupõe que os conceitos são coisas intrinsecamente relacionais, sendo impossível compreendê-los isoladamente, visto que o conhecimento do mundo, elaborado a partir de nossas experiências e vivências, formaria uma rede relacional coesa em nossa mente - a teoria. Assim, o significado de um conceito é dado pelos conceitos que a ele estão relacionados. Keil (1989) acredita que o fator que mantém a coesão entre os nódulos das redes são as relações causais existentes entre os conceitos que a compõem. Este fenômeno constitui a homeostase causal. É, pois, em função das relações causais existentes entre os conceitos que a estrutura se mantém coesa e em equilíbrio. Tal equilíbrio, todavia, pode ser rompido pela aprendizagem de uma nova informação, dando origem a uma reorganização da rede conceitual. Pois, uma vez que os diferentes conceitos de um mesmo domínio de conhecimento, ou os diferentes atributos de um mesmo conceito se apresentam altamente inter-relacionados em nossa mente, torna-se impossível mudar um atributo sem afetar todos os outros que fazem parte desta rede conceitual.

Um dos principais objetivos deste estudo foi investigar se os atributos categorizados formam uma homeostase causal, o que implica em verificar se os conceitos que formam a rede apresentam uma lógica interna, de modo que um não exclua o outro, mas que conjuntamente evidenciem a formação de uma rede de relações causais.

Os autores deste trabalho acreditam que é possível perceber uma coerência interna entre os atributos arrolados pelos alunos em cada um dos conceitos. Como anteriormente analisado, para os alunos do $1^{\circ}$ ano, o conceito de deficiência envolve aspectos referentes às dificuldades e incapacidades, resultantes de alterações motoras, funcionais e emocionais que, por sua vez, geram emoções negativas e afastam a pessoa portadora de deficiência da normalidade, criam preconceitos contra ela e, conseqüentemente, levam à exclusão social. Coerentemente, para este grupo de alunos, o conceito de reabilitação está também fortemente associado a aspectos emocionais os quais criam a necessidade de inclusão social e da melhoria da qualidade de vida. Em resumo, em ambos os conceitos estão presentes diferentes preocupações de caráter sócio-emocional aliado a certa negligência para com os aspectos técnicos que, certamente, também fazem parte do processo.

Por outro lado, é possível notar que mudanças geradas pelos mecanismos de aprendizagem no decorrer do curso de graduação levaram a uma reorganização dos conceitos como um todo, e não apenas em alguns dos seus atributos. Assim, para os sujeitos do $4^{\circ}$ ano, o conceito de deficiência se apresenta mais associado à incapacidade $e$ dependência, envolvendo aspectos funcionais e motores. Como decorrência, a reabilitação visa recuperar as capacidades anteriores à aquisição da deficiência e levar a uma melhora funcional e da qualidade de vida do indivíduo, tendo o terapeuta um papel ativo neste processo. Coerentemente, há uma ênfase nos aspectos mais técnicos da profissão, sendo quase totalmente desconsideradas questões relacionadas a aspectos emocionais e sociais, presentes no cotidiano das pessoas com deficiência e tão importantes para a reabilitação destas. Tais críticas ao tecnicismo podem ser encontradas nos trabalhos de vários autores (Marques, 2000; Pontes, 2002; Trelha \& Santos, 2003; Moraes, 2004), preocupados com a formação do fisioterapeuta.

Em resumo, os resultados desta pesquisa indicam que, em termos gerais, a hipótese central do mesmo foi confirmada, qual seja, ocorreu efetivamente uma mudança nos conceitos estudados no decorrer do curso. Mais especificamente, os atributos mais ligados ao senso comum, tais como os afetivos, foram progressivamente substituídos por aspectos mais técnico-científicos. Porém, a consideração isolada de aspectos emocionais e sociais, de um lado, e das implicações motoras e individuais da deficiência e do processo de reabilitação de outro lado, levaram a uma limitação da rede conceitual nestes dois extremos distintos do curso de graduação.

Mas, o que significam esses resultados? Quais as suas implicações para o exercício profissional? Será 
realmente importante priorizar questões técnicas do curso e deixar para um segundo plano outras mais voltadas para o lado humanista da profissão? O que está faltando para que esses profissionais saiam da graduação com uma rede conceitual mais ampla, capaz de considerar o indivíduo deficiente de maneira global, abrangendo o físico, o emocional e o social, requerendo, portanto, o trabalho de uma equipe de reabilitação multiprofissional?

Essas e outras questões poderão suscitar a realização de outros estudos na área de formação de conceitos dentro dos cursos de graduação na área da saúde, visando à melhoria do ensino prestado a esses futuros profissionais que participam do processo de reabilitação de pessoas com deficiência. É o que desejam os autores deste trabalho.

$\mathrm{Na}$ verdade, mais do que um mero desejo, a realização de trabalhos similares é uma necessidade em face de uma limitação crucial deste estudo, que deve ser claramente apontada: a reduzida capacidade de generalização dos seus dados. Tal limitação decorre do fato desta pesquisa ter trabalhado com um reduzido número de participantes, oriundos de uma única instituição privada de um estado brasileiro. Neste sentido, não é possível generalizar seus resultados para outras instituições, privadas e particulares, dos diversos estados da Federação. $\mathrm{Na}$ realidade, o que se pode afirmar é que ela retrata, com alguma segurança, as peculiaridades de um curso de graduação da instituição analisada. Daí o caráter de estudo exploratório destacado no seu título.

Não obstante essa limitação, os autores acreditam útil e oportuna a divulgação deste trabalho na medida em que poderá contribuir para a realização de outros estudos que visem aumentar e/ou verificar a generalidade dos resultados. Tal contribuição advém, dentre outros possíveis aspectos, da proposta de um instrumento para coletar os dados, da explicitação de um procedimento para avaliar os atributos que fazem parte ou estão comumente associados aos conceitos, da sugestão de um sistema de categorias para agrupar os dados e finalmente, mas não menos importante, da divulgação de um referencial teórico para análise e interpretação dos resultados. Aproveitadas tais contribuições, novos estudos serão mais que bem-vindos.

\section{Referências}

Amiralian, M.L.T.; Pinto, E.B.; Ghirardi, M.I.G.; Lichtig, I; Masini, E.F.S.; Pasqualin, L. (2000). Conceituando deficiência. Revista de Saúde Pública, 34 (I), 97-I03.

Brasil. Ministério da Saúde (1993). Coordenação de Atenção a Grupos Especiais. Programas de Atenção à Saúde da Pessoa Portadora de Deficiência. Atenção à Pessoa Portadora de Deficiência no Sistema Único de Saúde: planejamento e organização de serviços. Brasília: Secretaria de Assistência à Saúde.

Brasil. Ministério da Saúde. Secretaria de Assistência à Saúde (2003). Manual de Legislação em Saúde da Pessoa Portadora de Deficiência. Brasília: Ministério da Saúde.

Keil, F.C. (1989). Concepts, kinds, and cognitive development. Cambridge, MA, MIT Press.

Lomônaco, J.F.B. (1997). A natureza dos conceitos: visões psicológicas. Tese de Livre-docência, Instituto de Psicologia da Universidade de São Paulo, São Paulo-SP.

Marques, A.P. (2000). Diretrizes curriculares para os cursos de Fisioterapia. Revista de Fisioterapia da Universidade de São Paulo, 7 (I/2), p. i-ii.

Moraes, L.R.S (2004). A formação do fisioterapeuta quanto à inclusão escolar de crianças com deficiência física. Dissertação de Mestrado, Universidade Presbiteriana Mackenzie, São Paulo-SP.

Murphy, G.L.; Medin, D.L. (1985). The role of theories in conceptual coherence. Psychological Review, 92 (3), 289-316.

Oliveira, M.B. (1994). Rumo a uma teoria dialética dos conceitos. Em P.C.C. Abrantes (org.). Epistemologia e Cognição. (pp. 25-68). Brasília: Editora Universidade de Brasília.

Pontes, J. F. (2002). O fisioterapeuta: sua formação e os indícios de uma prática educativa. Tese de Doutorado, Instituto de Psicologia da Universidade de São Paulo, São Paulo-SP.

Prefeitura Municipal de São Paulo (2003). Proposta para a construção da política municipal de atenção à pessoa com deficiência. São Paulo.

Rocha, E.F. (1999). Do corpo orgânico ao corpo relacional: uma proposta de deslocamento dos fundamentos e práticas de reabilitação da deficiência. Tese de Doutorado, Instituto de Psicologia da Universidade de São Paulo, São Paulo.

Rocha, E.F. (2006). Deficiência e reabilitação: questões históricas e epistemológicas. Em: E. F. Rocha (org.) 
Reabilitação de pessoas com deficiência. (pp. 9-60). São Paulo: Editora Roca.

Siegel, S. (198I). Estatística não-paramétrica para as ciências do comportamento. São Paulo: Editora McGraw-Hill do Brasil.

Smith, E.E.; Medin, D.L. (198I). Categories and concepts. Cambridge, MA, Harvard University Press.
Trelha, C.S.; Santos, R.B. (2003). A comunidade como sala de aula: experiência de nove anos do curso de fisioterapia em um projeto multiprofissional e interdisciplinar. Fisioterapia em Movimento, 16 (I), 4I-46.

Recebido em: 14/12/2005

Revisado em: 18/07/2006

Aprovado em: 01/08/2006

\section{Sobre os autores}

José Fernando Bitencourt Lomônaco (jlblusp@usp.br) é Professor Associado (Livre-Docente) do Instituto de Psicologia da Universidade de São Paulo e Membro Titular da Academia Paulista de Psicologia

Ana Paula Martins Cazeiro (cazeiro@uol.com.br) é mestranda do Programa de Psicologia Escolar e do Desenvolvimento Humano do Instituto de Psicologia da Universidade de São Paulo.

Andréia Menandro Ferreira (andreiamdeia@yahoo.com) é mestre em Neurociências e Comportamento pelo Instituto de Psicologia da Universidade de São Paulo.

Endereço para correspondência

José Fernando Bitencourt Lomônaco

Rua Matheus Grou, 79, apto 62, São Paulo, CEP 054I5-050. 